\section{Kidney \\ Blood Pressure Research}

\title{
Effect of Nutritional Status on Human Paraoxonase-1 Activity in Patients with Chronic Kidney Disease
}

\author{
Ferenc Sztanek ${ }^{\mathrm{a}} \quad$ Ildikó Seres $^{\mathrm{a}} \quad$ Mariann Harangia $^{\mathrm{a}} \quad$ Lajos Lőcsey $^{\mathrm{b}} \quad$ Péter Koncsos $^{\mathrm{a}}$ \\ György Paragha
}

aFirst Department of Medicine, 'Institute of Surgery, University of Debrecen, Medical and Health Science Center, Debrecen

\section{Key Words}

Paraoxonase - Obesity - Nutritional state - C-reactive protein - Chronic kidney disease • Reverse epidemiology $\bullet$ Hemodialysis

\begin{abstract}
Background/Methods: The association between nutritional status, antioxidant human paraoxonase-1 (PON1) activity and low grade inflammation in hemodialized (HD) patients with chronic kidney disease (CKD) is unclear. The aim of this study was to determine PON1 paraoxonase and lactonase activities, ADMA, adiponectin and leptin concentrations, and to clarify the relationship between paraoxonase activity and a set of cardiovascular risk factors in malnourished, normal weight and obese HD patients; 114 HD patients with end-stage renal failure were enrolled. Results: Leptin levels were significantly higher and PON1 paraoxonase activities were significantly lower in obese patients compared to the other groups. Plasma adiponectin concentration was significantly lower in obese subjects compared to malnourished patients. Paraoxonase activity was negatively correlated with CRP level in HD and malnourished patients. Furthermore, we found significant inverse correlation between paraoxonase activity and BMI in the whole patient group. In multiple regression analysis, PON1 lactonase activity, CRP level and leptin concentration proved to be independent predictors of paraoxonase activity. Conclusion: Despite the previous findings of reverse epidemiology for the mortality rate of HD patients, further studies are needed to clarify the effects of nutritional state on atherosclerosis in obese and malnourished patients with end-stage renal failure.
\end{abstract}




\section{Kidney Blood Pressure Research}

Kidney Blood Press Res 2012;36:310-319

\begin{tabular}{l|l}
\hline DOI: $10.1159 / 000343383$ & (C) 2012 S. Karger AG, Basel
\end{tabular}

Published online: December 12, 2012

www.karger.com/kbr

tanek/Seres/Harangi/Lőcsey/Koncsos/Paragh: Nutritional Status and PON1 in Chronic Kidney Disease

\section{Introducion}

Cardiovascular diseases are the major cause of morbidity and mortality in chronic kidney disease (CKD) patients. Previous studies have suggested that traditional risk factors alone might not explain the higher prevalence and incidence of cardiovascular diseases in CKD patients on hemodialysis (HD) treatment $[1,2]$. Non-traditional risk factors, such as inflammation, oxidative stress and malnutrition are gaining acceptance in CKD especially in HD patients [3]. Although traditional risk factors for cardiovascular diseases have been shown to correlate with an unfavorable outcome in the general population, these factors appear to be protective and are associated with an improved survival in patients with chronic heart disease. In the last decades, several studies have published this unexpected and paradoxical phenomenon in patients with chronic heart disease referred to as „reverse epidemiology"; both C-reactive protein (CRP) as a marker of inflammation and (pre)albumin as a marker of nutritional status have been shown to be important independent predictors of mortality. Therefore, it is conceivable that both malnutrition and inflammation - referred to as the malnutrition-inflammation complex syndrome [4] - may be related to the reverse epidemiology [5].

Most of the HD patients have some degree of malnutrition; protein and energy depletion have been associated with increased morbidity and mortality in this population in several previous studies [6,7]. The available evidence suggests that low protein and energy intake in CKD along with the catabolic consequences of HD therapy may lead to the development of uremic malnutrition [6]. Numerous studies have shown that markers of malnutrition and inflammation, such as low body mass index (BMI), elevated CRP and increased plasma concentration of asymmetric dimethylarginine (ADMA), were strong independent predictors of cardiovascular mortality in CKD $[3,8]$.

Inflammation contributes to the development of cardiovascular disease by increasing vascular calcification and endothelial dysfunction in chronic kidney disease. On the other hand, various studies have concluded that CRP levels reflect well the degree of inflammation in hemodialyzed patients with metabolic syndrome and abdominal obesity [9-11].

Adipose tissue possesses various functions as energy storage and secretion of a number of adipocytokines including leptin, adiponectin with potential endocrine functions $[12,13]$. Adiponectin have been shown to be inversely correlated with insulin resistance and cardiovascular diseases in obese or overweight patients. Adiponectin levels have been found to be decreased in obesity and increased during weight loss; however, CKD has been associated with markedly elevated levels of adiponectin probably due to its decreased renal excretion $[13,14]$. Previously, it has been demonstrated that adiponectin has potential antiinflammatory and anti-atherogenic properties due to its modulatory effect on endothelial adhesion molecules acting as protective factor against atherogenesis [15].

Another adipokine, leptin regulates the amount of body fat, food intake and energy homeostasis; leptin levels show positive correlation with body fat mass [16, 17]. Serum leptin levels have been previously reported to be elevated in patients with chronic renal failure and to correlate with C-reactive protein levels suggesting that inflammation may be an important factor in the development of hyperleptinemia in CKD [18].

Both obesity and chronic inflammation enhance oxidative stress that leads to the oxidative modification of lipoprotein particles resulting in accelerated atherogenesis. Human serum paraoxonase (PON1) is an HDL-associated antioxidant enzyme which prevents lowdensity lipoprotein (LDL) from lipid peroxidation. In our previous work, we reported lower PON1 paraoxonase activity in HD patients $[19,20]$. Previous studies have also demonstrated that PON1 paraoxonase activity was inversely associated with cardiovascular risk [21]; serum PON1 paraoxonase activity was shown to correlate negatively with the degree of oxidative stress $[22,23]$. Several data suggest that PON1, which metabolizes a number of substrates such as paraoxon and phenylacetate, could also hydrolyze various esters, carbonates, thioesters and thiolactones via its lactonase activity [24]. A possible physiological substrate may be the homocysteine thiolactone known as a risk factor in atherosclerosis: metabolic 


\section{Kidney \\ Blood Pressure Research}

Kidney Blood Press Res 2012;36:310-319

\begin{tabular}{l|l}
\hline DOI: $10.1159 / 000343383$ & (c) 2012 S. Karger AG, Basel
\end{tabular}

Published online: December 12, 2012

www.karger.com/kbr

conversion of homocysteine to thiolactone and protein homocysteinylation by thiolactone may play role in homocysteine-induced vascular damage $[25,26]$.

We hypothesized that the changes in PON1 paraoxonase and lactonase activity in HD patients are associated with their nutritional status and may contribute to the increased risk of accelerated atherosclerosis in CKD. Therefore, the aim of this study was to determine PON1 paraoxonase and lactonase activities, ADMA, adiponectin, leptin concentrations and to reveal the relationship between paraoxonase activity and cardiovascular risk factors in malnourished and obese HD patients.

\section{Patients and Methods}

\section{Study population}

One hundred fourteen patients receiving hemodialysis three times weekly between 2005 and 2009 were enrolled in the study. The mean duration of dialysis was 46 months and ranged from 4 to 140 months; each hemodialysis treatment lasted four hours. We excluded patients with alcoholism, liver disease, elevated liver enzymes, recent myocardial infarction $(38,2 \%$ of patients had a previous history of angina pectoris or ischaemic heart disease), endocrine diseases (thyroid and parathyroid diseases, pituitary and adrenal gland disorders, etc.), pregnancy, lactation, patients on lipid-lowering therapy and smokers. We excluded the patients with myocardial infarction after the 3 months from the symptoms onset with $Q$ wave on the ECG. According to their BMI, patients were divided into three goups: malnourised (BMI $<20 \mathrm{~kg} / \mathrm{m} 2)$, normal weight $(20 \mathrm{~kg} / \mathrm{m} 2 \leq \mathrm{BMI} \leq 30 \mathrm{~kg} / \mathrm{m} 2)$ and obese (BMI $>30 \mathrm{~kg} / \mathrm{m} 2)$ groups. Patients gave a written, informed consent to participate, and the study was performed according to the requirements of the Ethical Committee of the Medical and Health Science Center, University of Debrecen, as well as the Code of Ethics of the World Medical Association.

\section{Blood sampling}

After 12 hours of fasting, $10 \mathrm{ml}$ venous blood sample was taken between 7.30 and 8.00 in the morning before dialysis. Lipid parameters and homocysteine concentrations were determined in fresh sera. The sera for enzyme activity measurements and for ELISA determinations were kept at - $70 \mathrm{oC}$ before analysis.

\section{Measurement of homocysteine and lipid parameters}

Fasting plasma total Hcy concentrations were determined by enzyme-linked immunoassay and automated fluorescence polarization analyzer (FPIA, IMX System, Abbott Diagnostics, Rome, Italy). This assay is a fluorescence polarization immunoassay based on the highly selective enzymatic conversion of homocysteine to S-adenosyl-L-homocysteine, which is then recognized by a monoclonal antibody.

Serum cholesterol and triglyceride levels were measured by using enzymatic, colorimetric tests (GPO-PAP, Modular P-800 Analyzer, Roche/Hitachi), while high-density lipoprotein cholesterol (HDL-C) was assessed by a homogenous, enzymatic, colorimetric assay (Roche HDL-C plus 3rd generation). LDLcholesterol was measured by homogenous, enzymatic, colorimetric assay (Roche LDL-C plus 2rd generation, Basel, Switzerland). The tests were performed according to the recommendation of the manufacturer.

\section{Analysis of PON1 paraoxonase activity}

PON1 paraoxonase activity was measured as previously described [19, 20]. Briefly, we used paraoxon (0,0-diethyl-0-p-nitrophenylphosphate, Sigma) as substrate, and the generation of 4-nitrophenol was measured spectrophotometrically. $50 \mu \mathrm{l}$ serum was dissolved in $1 \mathrm{ml}$ Tris/HCl buffer $(100 \mathrm{mmol} / \mathrm{l}, \mathrm{pH}=8.0)$ containing $2 \mathrm{mmol} / \mathrm{l} \mathrm{CaCl} 2$ and $5.5 \mathrm{mmol} / \mathrm{l}$ paraoxon. We measured the absorbance at $412 \mathrm{~nm} \mathrm{(25} \mathrm{oC),} \mathrm{using}$ a Hewlett-Packard 8453 UV-visible spectrophotometer. Enzyme activity was calculated using the molar extinction coefficient $17100 \mathrm{M}-1 \mathrm{~cm}-1$. One unit of paraoxonase activity is defined as $1 \mathrm{nmol}$ of 4 -nitrophenol formed per minute under the assay conditions mentioned above.

Analysis of PON1 arylesterase activity

Arylesterase activity was measured spectrophotometrically. The assay contained $1 \mathrm{mM}$ phenylacetate in $20 \mathrm{mM}$ Tris/ $\mathrm{HCl} \mathrm{pH}$ 8.0. The reaction was started by the addition of the serum and the increase in 


\section{Kidney \\ Blood Pressure Research}

Kidney Blood Press Res 2012;36:310-319

\begin{tabular}{l|l}
\hline DOI: $10.1159 / 000343383$ & (c) 2012 S. Karger AG, Basel
\end{tabular}

Published online: December 12, 2012

www.karger.com/kbr

zztanek/Seres/Harangi/Lőcsey/Koncsos/Paragh: Nutritional Status and PON1 in Chronic Kidney Disease

absorbance was read at $270 \mathrm{~nm}$ as already described [20,27]. Blanks were included to correct the spontaneous hydrolysis of phenylacetate. Enzyme activity was calculated using a molar extinction coefficient of $1310 \mathrm{M}-1 \mathrm{~cm}-1.1$ unit $(\mathrm{U})$ is defined as $1 \mu \mathrm{mol}$ phenylacetate hydrolyzed per minute.

Analysis of PON1 lactonase activity

PON1 lactonase activity was measured by a commercially available assay kit (Alfresa Auto HTLase; Alfresa Pharma Corporation, Japan). This kit utilizes gamma-thiobutyrolactone as substrate and Ellman's procedure to monitor the accumulation of free sulfhydryl groups via coupling with 5,5-dithiobis(2nitrobenzoic acid) [28]. Intra-assay CV was less than 6\%.

\section{Paraoxonase Genotyping}

PON1-55 and PON1-192 polymorphisms were determined using Light Cycler real-time technology based on fluorescence resonance energy transfer combined with melting point analysis as published previously [29]. Briefly, the regions of the PON1 gene surrounding the PON1-55 and PON1-192 polymorphisms resulting in 151- and 138-bp amplicon sizes were amplified. The sensor probe applied for PON1-55 genotyping was labeled with 5 -LC Red 640 dye, while to that for PON1-192 LC Red 705 fluorophore was attached. Both detection probe sets were located upstream at a distance of 2 nucleotides from each other. Both primers and fluorescence labeled probes were synthesized by TIB Molbiol Co. (Berlin, Germany). Polymerase chain reaction and melting curve analysis were performed in $20 \mu \mathrm{l}$-volume glass capillaries (Hoffmann-La Roche). During the melting point analysis followed by an ultrafast polymerase chain reaction, fluorescence intensity was monitored. Melting peaks were calculated from the melting curves by plotting the negative derivative of the fluorescence signal against temperature.

ADMA measurement

ADMA concentrations in serum of hemodialyzed patients were measured with commercially available ELISA kit (ADMA- ELISA, DLD Diagnostika GmbH, Hamburg, Germany). ADMA concentrations in samples were measured by a competitive enzyme immunoassay with intra-assay CVs ranging from $4.5 \%$ to $7.5 \%$, and inter-assay CVs ranging from $8.3 \%$ to $10.3 \%$. Measurements of ADMA level in sera were performed according to the manufacturer's instructions.

\section{Adiponectin and Leptin Measurement}

Total adiponectin and leptin concentrations in serum of hemodialyzed patients were measured with commercially available ELISA kits (Human Total Adiponectin/Acrp30 Quantikine and Human Leptin Quantikine Immunoassays, R\&D Systems, Minneapolis, USA; ADMA- ELISA, DLD Diagnostika GmbH, Hamburg, Germany). Adiponectin assay employs the quantitative sandwich enzyme immunoassay technique with intra-assay CVs ranging from $2.5 \%$ to $4.7 \%$, and inter-assay CVs ranging from $6.8 \%$ to $6.9 \%$. Precision of leptin measurement was intra-assay CVs ranging from 3.0\% to 3.3\%, inter-assay CV-s from 3.5\% to 5.4\%.

\section{Statistical methods}

SAS for Windows 6.12 (SAS Institute Inc.) computer program was used for the statistical analysis. Normality of data distribution was tested by Kolmogorov-Smirnov test. One-way analysis of variance was used to compare different groups of HD patients. Data were expressed as means \pm SD in case of normal distribution, and medians and quartiles in case of non-normal distribution. Comparisons between groups were performed by analysis of variance (ANOVA with Tukey post test). In case of PON1 paraoxonase and lactonase activity we used median test and due to multiple testing Bonferroni-Holm correction was performed. Relationships between parameters were assessed by Pearson correlation analysis. We carried out multiple regression analysis (backward-stepwise method) to test which of the variables predicted best paraxonase activity. PON1-192 and PON1-55 genotype distribution for 3 groups with different body weights were analysed by chi-square test. 


\section{Kidney \\ Blood Pressure Research}

Table 1: Characteristics and laboratory parameters of the study populations. Values are mean \pm SD and median (quartiles)

\begin{tabular}{|c|c|c|c|c|}
\hline & Malnourished $(\mathrm{n}=21)$ & Normal $(n=51)$ & Obese $(n=42)$ & $\mathrm{p}$ \\
\hline Age (years) & $56.67 \pm 8.1$ & $61.78 \pm 10.7$ & $60.14 \pm 9.85$ & n.s. \\
\hline BMI $(\mathrm{kg} / \mathrm{m} 2)$ & $18.92 \pm 0.69 \mathrm{a}, \mathrm{c}$ & $25.71 \pm 2.8 \mathrm{a}, \mathrm{b}$ & $33.49 \pm 2.76 \mathrm{~b}, \mathrm{c}$ & $<0.001$ \\
\hline Triglyceride (mmol/l) & $1.85(1.0-2.7)^{c}$ & $2.64(0.98-4.3)^{b}$ & $3.49(1.03-5.95)^{b, c}$ & $<0.05$ \\
\hline Cholesterol (mmol/l) & $4.54 \pm 0.8 \mathrm{a}, \mathrm{c}$ & $5.3 \pm 0.95^{\text {a }}$ & $5.22 \pm 1.03^{c}$ & $<0.05$ \\
\hline LDL-cholesterol (mmol/l) & $2.47 \pm 0.73$ a & $3.08 \pm 0.92$ a & $2.89 \pm 1.01$ & $<0.05$ \\
\hline HDL-cholesterol (mmol/l) & $1.23 \pm 0.29$ & $1.2 \pm 0.26$ & $1.13 \pm 0.28$ & n.s. \\
\hline Glucose $(\mathrm{mmol} / \mathrm{l})$ & $5.24 \pm 2.2$ & $5.69 \pm 1.63$ & $5.22 \pm 1.49$ & n.s. \\
\hline Homocysteine $(\mu \mathrm{mol} / \mathrm{l})$ & $18.37 \pm 5.69$ & $23.9 \pm 9.57$ & $22.07 \pm 5.01$ & n.s. \\
\hline Creatinine $(\mu \mathrm{mol} / \mathrm{l})$ & $603.14 \pm 175.68$ & $640.87 \pm 200.39$ & $709.71 \pm 253.91$ & n.s. \\
\hline hsCRP (mg/l) & $9.06 \pm 5.65$ & $8.24 \pm 7.08$ & $11.55 \pm 7.97$ & n.s. \\
\hline Adiponectine $(\mathrm{ng} / \mathrm{ml})$ & $19.5 \pm 8.61^{c}$ & $16.03 \pm 6.44$ & $13.64 \pm 7.46^{c}$ & $<0.01$ \\
\hline Leptin $(\mathrm{pg} / \mathrm{ml})$ & $8.59 \pm 7.79 \mathrm{c}$ & $16.97 \pm 10.16^{b}$ & $52.13 \pm 38.84 b, c$ & $<0.01$ \\
\hline Paraoxonase activity (U/l) & $75.95(30.92-151.9) c^{*}$ & $51.82(15.86-87.78)$ & $48.84(22.94-74.74) \mathrm{c}^{*}$ & $<0.05$ \\
\hline Paraoxonase activity/HDL & $65.59 \pm 48.26$ & $54.96 \pm 42.08$ & $45.28 \pm 27.9$ & n.s. \\
\hline Lactonase activity (U/l) & $141.11(77.68-204.54)$ & $121.89(65.25-178.53)$ & $114.01(61.81-166.21)$ & n.s. \\
\hline ADMA (ng/ml) & $276.76 \pm 51.67$ & $253.99 \pm 75.96$ & $283.76 \pm 58.62$ & n.s. \\
\hline Arylesterase activity $(\mathrm{U} / \mathrm{l})$ & $105.98 \pm 14.65$ & $103.27 \pm 9.32$ & $101.87 \pm 14.12$ & n.s. \\
\hline Albumin (mg/l) & $37.6 \pm 2.3$ & $38.97 \pm 2.46$ & $38.83 \pm 2.15$ & n.s. \\
\hline
\end{tabular}

Table 2: Pearsons correlations between selected variables in the HD patients

\begin{tabular}{|c|c|c|c|c|c|c|c|}
\hline & BMI & PON1 & Lactonase & CRP & Adiponectine & Leptin & ADMA \\
\hline Age & 0,153 & $-0,077$ & $-0,134$ & 0,106 & 0,001 & $-0,013$ & 0,168 \\
\hline BMI & & $-0.314^{* *}$ & $-0,138$ & $\mathbf{0 , 3 1 3 ^ { * * }}$ & $-0,357^{* *}$ & $0,563 * * *$ & 0,023 \\
\hline PON1 & & & $0,366^{* *}$ & $-0.344^{* *}$ & 0.061 & $-0,293^{*}$ & $-0,084$ \\
\hline Lactonase & & & & $-0,318^{*}$ & 0,303* & 0,023 & $-0,314^{*}$ \\
\hline CRP & & & & & $-0,260^{*}$ & $-0,097$ & $-0,089$ \\
\hline Adiponectine & & & & & & $-0,180$ & 0,080 \\
\hline Leptin & & & & & & & 0,071 \\
\hline
\end{tabular}

\section{Results}

Studying the data of the 114 CKD patients treated with hemodialysis for more than six months, participants were divided into three groups according to their BMI as malnourished $(\mathrm{BMI}<20 \mathrm{~kg} / \mathrm{m} 2, \mathrm{~N}=21,11 \mathrm{M} / 10 \mathrm{~F})$, normal weight $(20 \leq \mathrm{BMI} \leq 30 \mathrm{~kg} / \mathrm{m} 2, \mathrm{~N}=51,24 \mathrm{M} / 27 \mathrm{~F})$ and overweight patients (BMI $>30 \mathrm{~kg} / \mathrm{m} 2, \mathrm{~N}=42,20 \mathrm{M} / 22 \mathrm{~F}$ ). Clinical and laboratory characteristics of the three groups are summarized in Table 1 . There were no significant differences among these groups in gender, age, duration of haemodialysis, smoking habits and diabetes.

Leptin levels were significantly higher $(\mathrm{p} \leq 0.001)$ and PON1 paraoxonase activities were significantly lower $(\mathrm{p}=0.019)$ in obese patients compared to the malnourished group but this difference is on the border of significance with Bonferroni-Holm correction (Table 1). There is no significant difference in PON1 activity between normal and obese patient groups, the difference between PON1 activity of normal and malnourished patients are also not significant, however the accompanying $p$ value $(p=0.0697)$ suggests further investigations with more cases. It must be noted that there was a significant correlation between PON1 activity and the BMI (Table 2). Plasma adiponectin concentration was significantly lower in obese subjects compared to the malnourished group. We did not find any significant differences between the groups in ADMA levels and no difference was found in homocysteine 


\section{Kidney \\ Blood Pressure Research}
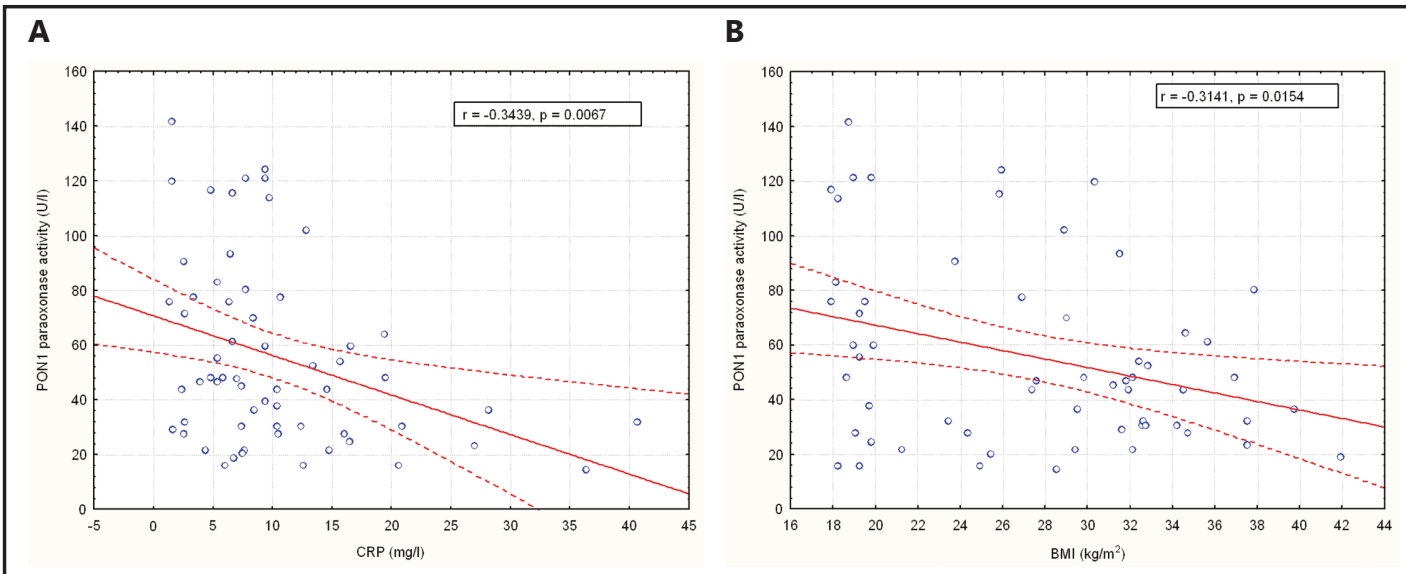

Fig. 1. Correlation between PON1 paraoxonase activities and CRP levels in patients (A). Correlation between paraoxonase activity and BMI in hemodialyzed patients (B).

levels, too. Lactonase activity was higher in malnourished patients compared to both of the obese and normal weight groups but this difference was not statistically significant (Table1).

PON1 paraoxonase activity negatively correlated with CRP level in all HD patients $(\mathrm{r}=-0.344, \mathrm{p}<0.01$, Table 2 and Fig. 1$)$ and in malnourished subjects $(\mathrm{r}=-0.519, \mathrm{p}<0.01$, not shown). We could not find any significant correlations between serum PON1 paraoxonase activity and CRP levels in obese and normal-weight HD patients. We found a significant positive correlation between BMI and CRP levels in all HD patients (Table 2) $(r=0.586, p<0.01$, in malnourished, $r=0.402, p<0.01$ and in obese subjects, $r=0.485, p<0.01$, respectively, not shown). Furthermore, we found a significant inverse correlation of PON1 paraoxonase activity and BMI in all patients on dialysis ( $\mathrm{r}=-0.314, \mathrm{p}<0.05$, Table 2$)$ and in the whole patient population ( $\mathrm{r}=-0.303, \mathrm{p}<0.05$, not shown). We could not detect significant correlation between serum PON1 paraoxonase activity and adiponectin levels in HD patients; however, a positive correlation was observed between these parameters in normal-weight HD patients $(\mathrm{r}=0.326, \mathrm{p}<0.05$, not shown). We found a positive correlation between adiponectin and PON1 lactonase activity ( $r=0.303, p<0.05$, not shown) and a significant negative correlation between PON1 lactonase activity and CRP levels ( $r=-0.318, p<0.05$, not shown) in all HD patients.

To test whether the association between PON1 paraoxonase activity and CRP levels in the univariate analysis was independent of age, BMI and other parameters, we carried out multiple regression analysis. Lactonase activity, CRP level and leptin concentration were independent predictors of PON1 paraoxonase activity adjusting age, BMI, ADMA and adiponectin to the model (Table 3 ).

The allelic frequencies and genotype distributions in the malnourished, normal-weight and obese HD patients are summarized in Table 4. The allelic frequencies were in accordance with the results of our previous studies [30, 31] and the literature [32, 33]; they followed the Hardy-Weinberg equilibrium. There were no significant differences between the studied groups.

As shown in Table 1, no significant differences were observed in serum HDL-cholesterol concentrations, glucose and CRP levels in each groups. Malnourished subjects had significantly lower triglyceride levels and significantly lower mean total and LDL-cholesterol concentrations than the normal weight and obese patients. Creatinine concentrations were similar in the three groups of patients, and plasma levels of albumin were also similar in malnourished, obese and normal weight subjects. 


\section{Kidney \\ Blood Pressure Research}

Kidney Blood Press Res 2012;36:310-319

\begin{tabular}{l|l}
\hline DOI: $10.1159 / 000343383$ & (c) 2012 S. Karger AG, Basel
\end{tabular}

Published online: December 12, 2012

www.karger.com/kbr

Sztanek/Seres/Harangi/Lőcsey/Koncsos/Paragh: Nutritional Status and PON1 in Chronic Kidney Disease
Table 3: Multiple regression analysis for PON1 as a dependent variable $\left(\mathrm{R}^{2}=0.211\right)$

\begin{tabular}{lccc}
\hline & Beta & $\mathrm{t}$ & $\mathrm{p}$-level \\
\hline Intercept & & 1.279 & $<0.05$ \\
Age & 0.012 & 0.078 & 0.938 \\
BMI & 0.024 & 0.115 & 0.909 \\
Lactonase & 0.406 & 2.331 & $\mathbf{0 . 0 2 7}$ \\
CRP & -0.488 & -2.798 & $\mathbf{0 . 0 0 9}$ \\
Adiponectine & -0.247 & -1.419 & 0.167 \\
Leptin & -0.411 & -2.069 & $\mathbf{0 . 0 4 7}$ \\
ADMA & 0.046 & 0.284 & 0.778 \\
\hline
\end{tabular}

Table 4: The allelic frequencies and genotype distributions in the malnourished, normal-weight and obese hemodialized patients

\begin{tabular}{lccc}
\hline & Malnourished & $\begin{array}{c}\text { Normal- } \\
\text { weight }\end{array}$ & Obese \\
\hline PON1-192 & 0.68 & 0.65 & 0.68 \\
Q: & 0.32 & 0.35 & 0.32 \\
R: & 0.474 & 0.441 & 0.472 \\
QQ: & 0.421 & 0.412 & 0.417 \\
QR: & 0.105 & 0.147 & 0.111 \\
RR: & 0.32 & 0.3 & 0.32 \\
PON1-55 & 0.68 & 0.7 & 0.68 \\
L: & 0.117 & 0.086 & 0.105 \\
M: & 0.412 & 0.429 & 0.421 \\
LL: & 0.471 & 0.485 & 0.474 \\
LM: & & & \\
MM: & & \\
\hline PON1-192 $\chi^{2=}=0.1955 \mathrm{p}=0.9955 ;$ \\
PON1-55 $\chi^{2=1.5417 \mathrm{p}=0.8192}$ \\
\hline
\end{tabular}

\section{Discussion}

Our previous studies have shown that paraoxonase and lactonase activities of PON1 enzyme are significantly decreased in chronic renal failure $[19,30]$. In the present work, we found higher PON1 paraoxonase activities in malnourished HD patients compared to obese patients, and similar changes in lactonase activities; however, it did not prove to be statistically significant, We detected a positive correlation between adiponectin and PON1 lactonase activity and a significant negative correlation between lactonase activity and CRP levels in all HD patients. This result suggests an impaired antioxidant status in CKD patients with higher BMI and supports the initial hypothesis that the decrease in paraoxonase and lactonase activities through the reduction of their antiatherogenic effects may contribute to accelerated atherogenesis in CKD, especially in obese hemodialyzed patients.

Previous studies have demonstrated a direct relationship between BMI and CKD risk $[34,35]$ and have shown a correlation between BMI and the increasing prevalence of chronic renal failure in overweight and obese patients. In our study, a moderate increase in serum creatinine level was found parallel with BMI. It has been previously suggested that this increase may be linked to the progression of CKD in HD patients; however we could not demonstrate a significant difference between the obese and malnourished groups. Moreover, there was no connection between BMI and serum albumin levels in HD patients supporting the findings of other studies where albumin was an unreliable marker of the nutritional status in CKD and elderly patients [36, 37].

The role of leptin in kidney function has not been completely defined so far. It is thought to be a potential salt-regulating factor and may function pathophysiologically as a common link to obesity and hypertension [38]. It has been also recognized that hyperleptinemia was linked to renal structural changes associated with obesity. Although leptin is partly cleared by the kidneys and patients with either kidney disease or HD have been demonstrated to have higher leptin levels, our previous research showed that hyperleptinemia was not responsible for decreased paraoxonase activity in HD patients [39]. Therefore, hyperleptinaemia may be an independent predictor for the progression of renal diseases and for the increased risk of cardiovascular diseases in HD patients with higher BMI.

Oxidative stress and inflammation have been implicated in albuminuria and renal dysfunction in uremic patients. It has been previously shown that low adiponectin levels are 


\section{Kidney Blood Pressure Research}

Kidney Blood Press Res 2012;36:310-319

\begin{tabular}{l|l}
\hline DOI: $10.1159 / 000343383$ & (C) 2012 S. Karger AG, Basel
\end{tabular}

Published online: December 12, 2012

www.karger.com/kbr

Sztanek/Seres/Harangi/Lőcsey/Koncsos/Paragh: Nutritional Status and PON1 in Chronic Kidney Disease

associated with inflammation and atherosclerosis in CKD; however, we could not find any relationship between adiponectin and PON1 paraoxonase activity in the present study.

This result suggests that PON1 paraoxonase activity may be a reliable indicator regarding the progression of renal failure in malnourished patients compared with the obese HD group. Investigating the relationship of different variables (age, BMI, HDL-C, CRP and ADMA levels) to paraoxonase activity in multiple regression analysis, only PON1 lactonase activity, leptin and CRP levels proved to be independent predictors of PON1 paraoxonase activity. Several authors have demonstrated that higher BMI is associated with improved survival in overweight and obese CKD patients on maintenance hemodialysis compared to the general population [4, 40,41]. „Reverse epidemiology” in CKD is one of the most discussed and controversial topic regarding the mortality of HD patients. Reverse epidemiology suggests some beneficial effects of higher BMI in patients with CKD. Various studies have concluded that the presence of the malnutrition-inflammation complex syndrome may also explain the existence of reverse epidemiology in HD patients $[10,11,40]$. It seems that higher BMI itself is not beneficial but is a marker of lower catabolic rate. Thus, higher BMI and better prognosis are two independent consequences of a better metabolic status. In general, malnourished HD patients have worse prognosis than those with adequate body weight, whereas PON1 was higher in malnourished patients. These data indicate that PON1 is not involved in the mechanism of "reverse epidemiology", and that protective effect of PON1 is either lost in malnourished patients or is outweighed by other detrimental mechanisms in this group.

\section{Conclusion}

Our results show significantly lower activities of the antiatherogenic PON1 in obese HD patients compared to malnourished subjects. Despite our findings regarding the reverse epidemiology for the mortality of HD patients, further studies are needed to reveal the real effects of nutritional state on atherosclerosis in obese and malnourished CKD patients. There is growing evidence in the literature $[42,43]$ to support our initial hypothesis that the antioxidant properties of PON-1 enzyme are closely associated with PON1 paraoxonase activity and not with lactonase activity. Therefore, in the present study we have primarily investigated the relationship between PON1 paraoxonase activity and the antioxidant status in chronic kidney disease depending on nutritional status. Our goal was to evaluate the alteration of PON1 paraoxonase and lactonase activities and their correlations with nutrition levels in malnourished, normal-weight and obese hemodialyzed patients. Our result suggests that PON1 paraoxonase activity may be a reliable marker regarding the progression of renal failure in malnourished subjects compared with the obese hemodialyzed patients. To our best knowledge, there is no specific substance or enzyme, which can determine the lactonase activity of PON1 enzyme. Otherwise, we have shown in our previous study that the PON1 lactonase activity was not independent of PON1 paraoxonase activity in patients with chronic kidney disease [30].

\section{Conflict of Interests}

The authors of this manuscript state that they have no conflicts of interest.

\section{Aknowledgements}

This work was supported by a grant from the Hungarian Scientific Research Fund (OTKAK84196), and by the TÁMOP 4.2.1./B-09/1/KONV/2010-0007, TÁMOP4.2.2/B-10/1-2010-0024 and TÁMOP-4.2.2.A-11/1/KONV-2012-0031 projects. The projects are co-financed by the European Union and the European Social Fund. 


\section{Kidney \\ Blood Pressure Research}

Kidney Blood Press Res 2012;36:310-319

\begin{tabular}{l|l}
\hline DOI: $10.1159 / 000343383$ & (c) 2012 S. Karger AG, Basel
\end{tabular}

Published online: December 12, 2012

www.karger.com/kbr

\section{References}

1 Kalantar-Zadeh K, Stenvinkel P, Pillon L, Kopple JD: Inflammation and nutrition in renal insufficiency. Adv Ren Replace Ther 2003;10:155-169.

-2 Axelsson J, Stenvinkel P: Role of fat mass and adipokines in chronic kidney disease. Curr Opin Nephrol Hypertens 2008;17:25-31.

-3 Zoccali C, Mallamaci F, Tripepi G: Novel cardiovascular risk factors in end-stage renal disease. J Am Soc Nephrol 2004;15:S77-80.

-4 Colman S, Bross R, Benner D, Chow J, Braglia A, Arzaghi J, Dennis J, Martinez L, Baldo DB, Agarwal V, Trundnowski T, Zitterkoph J, Martinez B, Khawar OS, Kalantar-Zadeh K: The Nutritional and Inflammatory Evaluation in Dialysis patients (NIED) study: overview of the NIED study and the role of dietitians. J Ren Nutr 2005;15:231-243.

-5 Nurmohamed SA, Nubé MJ: Reverse epidemiology: paradoxical observations in haemodialysis patients. Neth J Med 2005;63:376-381.

6 Ikizler TA: Protein and energy: recommended intake and nutrient supplementation in chronic dialysis patients. Semin Dial 2004;17:471-478.

7 Cohen SD, Kimmel PL: Nutritional status, psychological issues and survival in hemodialysis patients. Contrib Nephrol 2007;155:1-17.

-8 Brunini TM, Moss MB, Siqueira MA, Santos SF, Lugon JR, Mendes-Ribeiro AC: Nitric oxide, malnutrition and chronic renal failure. Cardiovasc Hematol Agents Med Chem 2007;5:155-161.

-9 Brooks GC, Blaha MJ, Blumenthal RS: Relation of C-reactive protein to abdominal adiposity. Am J Cardiol 2010;106:56-61.

10 Santoro D, Bellinghieri G, Conti G, Pazzano D, Satta E, Costantino G, Savica V: Endothelial dysfunction in chronic renal failure. J Ren Nutr 2010;20:S103-108.

$>11$ Ishimura E, Okuno S, Tsuboniwa N, Shoji S, Yamakawa T, Nishizawa Y, Inaba M: Relationship between fat mass and serum high-sensitivity C-reactive protein levels in prevalent hemodialysis patients. Nephron Clin Pract 2011;119:283-288.

12 Kershaw EE, Flier JS: Adipose tissue as an endocrine organ. J Clin Endocrinol Metab 2004;89:2548-2556.

-13 Axelsson J, Heimbürger 0, Stenvinkel P: Adipose tissue and inflammation in chronic kidney disease. Contrib Nephrol 2006;151:165-174.

14 Axelsson J, Stenvinkel P: Role of fat mass and adipokines in chronic kidney disease. Curr Opin Nephrol Hypertens 2008;17:25-31.

15 Saito O, Saito T, Okuda K, Okuda K, Kotoda A, Akimoto T, Ando Y, Muto S, Ishikawa SE, Kusano E: Serum adiponectin and markers of endothelial injury in hemodialysis patients with arteriosclerosis obliterans. Clin Exp Nephrol 2008;12:58-64.

-16 Silha JV, Krsek M, Skrha JV, Sucharda P, Nyomba BL, Murphy LJ: Plasma resistin, adiponectin and leptin levels in lean and obese subjects: correlations with insulin resistance. Eur J Endocrinol 2003;149:331-335.

17 Considine RV: Human leptin: an adipocyte hormone with weight-regulatory and endocrine functions. Semin Vasc Med 2005;5:15-24.

18 Mak RH, Cheung W, Cone RD, Marks DL: Leptin and inflammation-associated cachexia in chronic kidney disease. Kidney Int 2006;69:794-797.

19 Paragh G, Seres I, Balogh Z, Varga Z, Karpati I, Matyus J, Ujhelyi L, Kakuk G: The serum paraoxonase activity in patients with chronic renal failure and hyperlipidemia. Nephron 1998;80:166-170.

20 Paragh G, Asztalos L, Seres I, Balogh Z, Locsey L, Karpati I, Matyus J, Katona E, Harangi M, Kakuk G: Serum paraoxonase activity changes in uremic and kidney-transplanted patients. Nephron 1999;83:126-131.

-21 Senti M, Tomás M, Elosual R, Sala J, Masiá R, Marrugat J: The paraoxonase-1 codon 192 polymorphism is associated with fasting total cholesterol and LDL-cholesterol concentrations only in postmenopausal women. The REGICOR study. Clin Chem Lab Med 2002;40:677-683.

22 Rozenberg O, Rosenblat M, Coleman R, Shih DM, Aviram M: Paraoxonase (PON1) deficiency is associated with increased macrophage oxidative stress: studies in PON1-knockout mice. Free Radic Biol Med 2003;34:774-784.

23 Beltowski J, Wójcicka G, Jamroz A: Leptin decreases plasma paraoxonase 1 (PON1) activity and induces oxidative stress: the possible novel mechanism for proatherogenic effect of chronic hyperleptinemia. Atherosclerosis 2003;170:21-29. 


\section{Kidney \\ Blood Pressure Research}

Kidney Blood Press Res 2012;36:310-319

\begin{tabular}{l|l}
\hline DOI: $10.1159 / 000343383$ & (c) 2012 S. Karger AG, Basel
\end{tabular}

Published online: December 12, 2012

www.karger.com/kbr

Sztanek/Seres/Harangi/Lőcsey/Koncsos/Paragh: Nutritional Status and PON1 in Chronic Kidney Disease

24 Costa LG, Vitalone A, Cole TB, Furlong CE: Modulation of paraoxonase (PON1) activity. Biochem Pharmacol 2005;69:541-550.

25 Khersonsky 0, Tawfik DS: Structure-reactivity studies of serum paraoxonase PON1 suggest that its native activity is lactonase. Biochemistry 2005;44:6371-6382.

-26 Jakubowski H: The role of paraoxonase 1 in the detoxification of homocysteine thiolactone. Adv Exp Med Biol 2010;660:113-127.

-27 Eckerson HW, Romson J, Wyte C, La Du BN: The human serum paraoxonase polymorphism: identification of phenotypes by their response to salts. Am J Hum Genet 1983;35:214-227.

-28 Ellman GL, Courtney KD, Andres VJ, Feather SR: A new and rapid colorimetric determination of acetylcholinesterase activity. Biochem Pharmacol 1961;7:88-95.

29 Pocsai Z, Toth Z, Paragh G, Szeles G, Adany R: Rapid genotyping of paraoxonase 55 and 192 mutations by melting point analysis using real time PCR technology. Clin Chim Acta 2003;33:231-236.

- 30 Sztanek F, Seres I, Harangi M, Locsey L, Padra J, Paragh GJ, Asztalos L, Paragh G: Decreased paraoxonase 1 (PON1) lactonase activity in hemodialyzed and renal transplanted patients. A novel cardiovascular biomarker in end-stage renal disease. Nephrol Dial Transplant 2012;27:2866-2872.

31 Paragh G, Seres I, Harangi M, Pocsai Z, Asztalos L, Locsey L, Szeles G, Kardos L, Varga E, Karpati I, Adany R: Discordance in human paraoxonase-1 gene between phenotypes and genotypes in chronic kidney disease. Nephron Clin Pract 2009;113:46-53.

-32 Akhmedova SN, Yakimovsky AK, Schwartz EI: Paraoxonase 1 Met--Leu 54 polymorphism is associated with Parkinson's disease. J Neurol Sci 2001;184:179-182.

-33 Rainwater DL, Rutherford S, Dyer TD, Rainwater ED, Cole SA, Vandeberg JL, Almasy L, Blangero J, Maccluer JW, Mahaney MC: Determinants of variation in human serum paraoxonase activity. Heredity (Edinb) 2009;102:147-154.

-34 Hall JE, Crook ED, Jones DW, Wofford MR, Dubbert PM: Mechanisms of obesity-associated cardiovascular and renal disease. Am J Med Sci 2002;324:127-137.

35 Kramer HJ, Saranathan A, Luke A, Durazo-Arvizu RA, Guichan C, Hou S, Cooper R: Increasing body mass index and obesity in the incident ESRD population. J Am Soc Nephrol 2006;17:1453-1459.

-36 Friedman AN, Yu Z, Juliar BE, Nguyen JT, Strother M, Quinney SK, Li L, Inman M, Gomez G, Shihabi Z, Moe S: Independent influence of dietary protein on markers of kidney function and disease in obesity. Kidney Int 2010;78:693-697.

37 Bouillanne O, Hay P, Liabaud B, Duché C, Cynober L, Aussel C: Evidence that albumin is not a suitable marker of body composition-related nutritional status in elderly patients. Nutrition 2011;27:165-169.

-38 Yilmaz A, Kayardi M, Icagasioglu S, Candan F, Nur N, Gültekin F: Relationship between serum leptin levels and body composition and markers of malnutrition in nondiabetic patients on peritoneal dialysis or hemodialysis. J Chin Med Assoc 2005;68:566-570.

- 39 Varga Z, Paragh G, Seres I, Kakuk G, Karanyi Z, Karpati I, Matyus J, Csongradi E, Juhasz A, Balla J, Bajnok L: Hyperleptinemia is not responsible for decreased paraoxonase activity in hemodialysis patients. Nephron Clin Pract 2006;103:114-120.

-40 Kalantar-Zadeh K, Block G, Horwich T, Fonarow GC: Reverse epidemiology of conventional cardiovascular risk factors in patients with chronic heart failure. J Am Coll Cardiol 2004;43:1439-1444.

-41 Shoji T, Shinohara K, Hatsuda S, Kimoto E, Fukumoto S, Emoto M, Tahara H, Koyama H, Ishimura E, Miki T, Tabata T, Nishizawa Y: Altered relationship between body fat and plasma adiponectin in end-stage renal disease. Metabolism 2005;54:330-334.

-42 Zhao Y, Ma Y, Fang Y, Liu L, Wu S, Fu D, Wang X: Association between PON1 activity and coronary heart disease risk: a meta-analysis based on 43 studies. Mol Genet Metab 2012;105:141-148.

43 Gbandjaba NY, Ghalim N, Hassar M, Berrougui H, Labrazi H, Taki H, Saile R, Khalil A: Paraoxonase activity in healthy, diabetic, and hemodialysis patients. Clin Biochem 2012;45:470-474. 